\title{
A rare variant of pilomatricoma: pseudobullous pilomatricoma
}

Hilal Kaya Erdoğan ${ }^{1 凶}$, Zeliha Kaya², Çiğdem Derya Aytop³, Ersoy Acer4

\begin{abstract}
Pilomatricoma (PM; calcifying epithelioma of Malherbe) is a benign tumor originating from the matrix of the hair follicles. Clinical types of the tumor are familial, perforating, multinodular, exophytic, anetodermic, and giant PM. The bullous type is seen only in 3 to $6 \%$ of cases. Because the bullous areas detected in PM are filled with lymphatic liquid, some authors use the term pseudobulla. This report presents a 26-year-old female patient that was diagnosed with pseudobullous PM based on clinical, radiologic, and histopathological findings, and the pathogenesis of the bullous appearance of PM is reviewed from the literature.
\end{abstract}

Keywords: case report, benign skin tumor, clinical types of pilomatricoma

Received: 9 June 2015 | Returned for modification: 10 July 2015 | Accepted: 20 August 2015

\section{Introduction}

Pilomatricoma (PM; calcifying epithelioma of Malherbe) is a benign tumor originating from the matrix of the hair follicles (1). Beta-catenin and Bcl-2 mutations have been found to be important in the pathogenesis of PM (2).

This report presents a 26-year-old female patient that was diagnosed with pseudobullous PM based on clinical, radiological, and histopathological findings.

\section{Case report}

A 26-year-old female patient presented to our outpatient clinic with the complaint of a nodule on her right arm. The lesion had existed for about 7 months, and the skin over the nodule had transformed into a pseudobulla 2 months earlier. There was no particular local trauma history at the site of the lesion. Her medical history was unremarkable and she did not have any similar cases of the disease in her family.

Upon dermatological examination, a solid, mobile, hard tumoral lesion approximately $1.1 \times 1.6 \mathrm{~cm}$ in diameter covered with bullous-like and soft skin was detected on the lateral aspect of the upper arm (Figure 1). Calcification of the lesion was determined radiologically (Figure 2).

For diagnosis and treatment, total excision of the lesion was performed. Histopathological examination of the excision material revealed tumor islets formed from ghost and basaloid cells surrounded by a well-demarcated fibrous capsule in the deep dermis (Figure 3).

Together with the clinical and histopathological findings, our case was diagnosed as pseudobullous PM.

\section{Discussion}

PM is most frequently seen on the head and neck region as a solid, painless, well-demarcated, and slow-growing dermal or subcutaneous nodule or tumor $(3,4)$. The overlying skin may be normal or have a bullous appearance (5). Familial, bullous, perforating, multi-nodular, exophytic, anetodermic, and giant clinical types have been reported in the literature. It is seen more frequently in

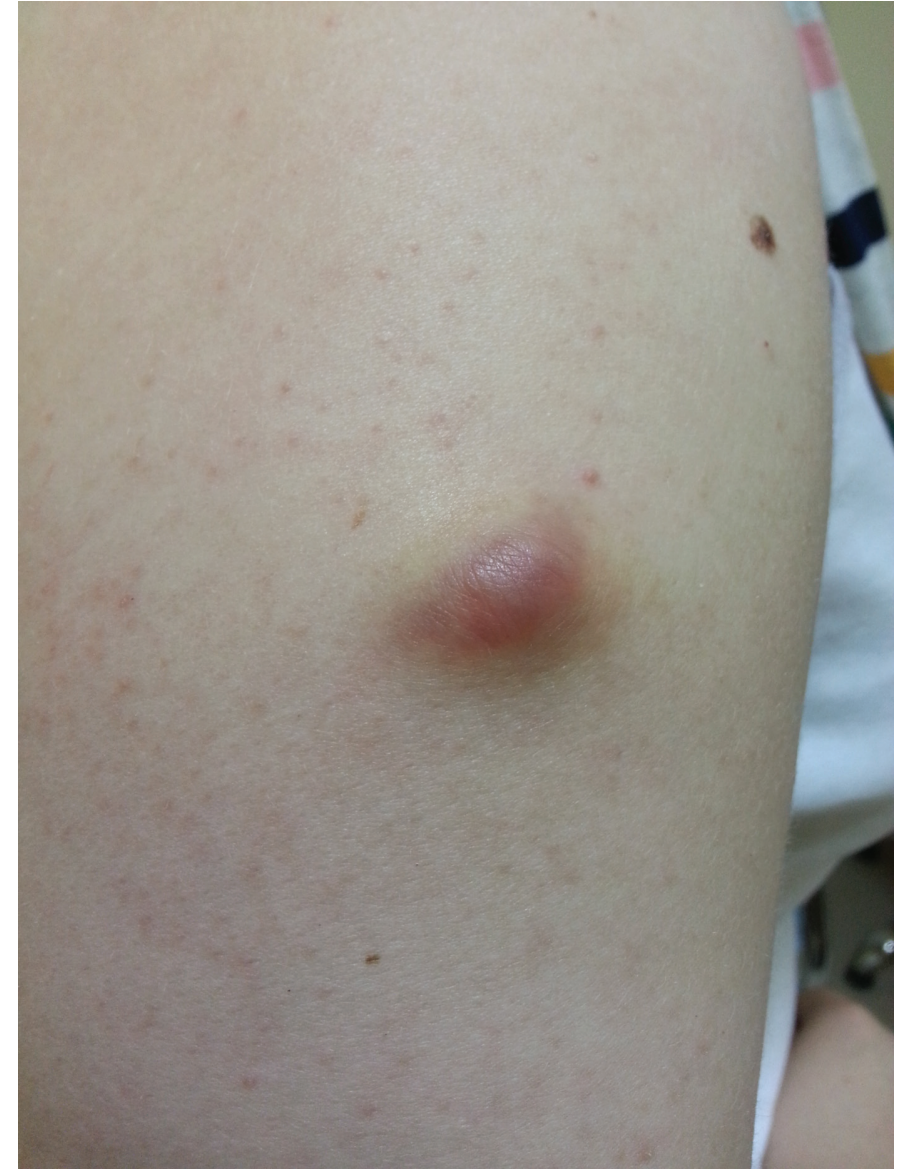

Figure 1 | Tumoral lesion covered with bullous-like soft skin, located on the lateral aspect of the upper arm.

women. It possesses a biphasic age distribution: $60 \%$ of cases appear under age 30, and the second peak occurs in the sixth and seventh decades of life $(1,2,6)$.

The bullous type of PM is seen in approximately 3 to $6 \%$ of cases (7). The bullous type of PM is covered with a thick, loose layer of skin (8). In contrast to other types, the bullous type occurs most commonly on the upper arm and shoulder regions (5).

Various theories, such as mechanical trauma, lymphatic obstruction, development of secondary anetoderma, and elastolytic enzymes, have been put forward to explain the bullous appearnce (8). 


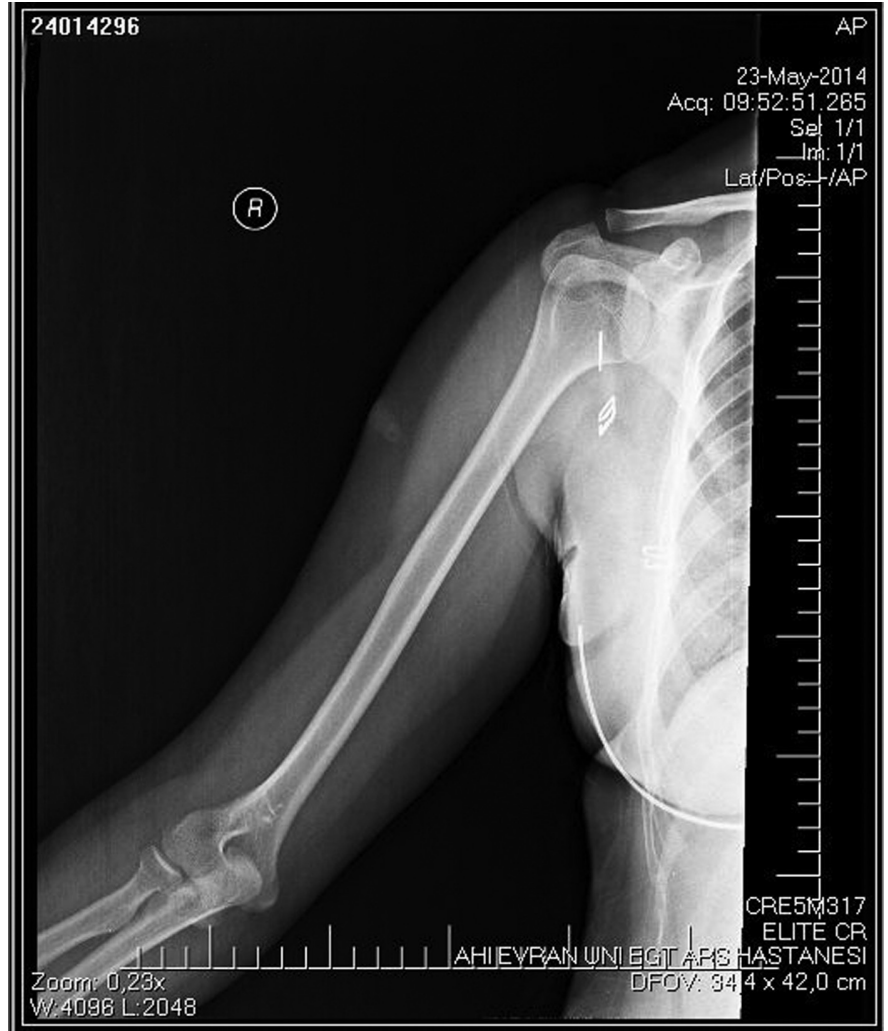

Figure 2 | Calcified tumoral lesion on X-ray.

The PM leads to lymphatic obstruction, congestion, and dilation due to pressure on the surrounding tissue, causing lymphatic leakage. This, in turn, results in edema and the bullous appearance in the surrounding dermis (the lymphangiectasia variant) $(6,8,9)$. There are also publications that state that the bullous appearance forms secondary to anetoderma. A reduction of elastic fibers and degeneration of collagen fibers is found in the anetodermic type $(8,9)$. Another theory is that, with the impact of the elastolytic enzymes secreted from the tumor cells and inflammatory cells, the lymph veins become damaged and dilated (9). Because the bullous areas detected in the PM are filled with lym-

\section{References}

1. Mansur AT, Serdar AZ, Erçin Z, Gündüz S, Aker F. The clinical and histopathologic features of 25 pilomatricoma cases. Turkderm. 2004;38:37-40. Turkish.

2. Chan JJ, Tey HL. Multiple pilomatricomas: case presentation and review of the literature. Dermatol Online J. 2010;16:2.

3. Haktanır NT, Demir Y, Şahin Ö, Bükülmez A, Tüzüner M. Pilomatricoma: a review of six pediatric cases with nine lesions. Turkish J Pediatr. 2009;51:44-8.

4. Julian CG, Bowers PW. A clinical review of 209 pilomatricomas. J Am Acad Dermatol. 1998;39:191-5.

5. Chen SY, Wu F, Qian Y, Zhu L, Tu YT, Huang CZ. Pilomatricoma with bullous appearance: a case report and review of literature. Int J Dermatol. 2011;50:615-8.

6. Akarsu S, Ilknur T, Kibar M, Özbağçıvan Ö, Özer E, Fetil E. Pseudobullous anetodermic pilomatricoma. Turkderm. 2013;47:114-6. Turkish.

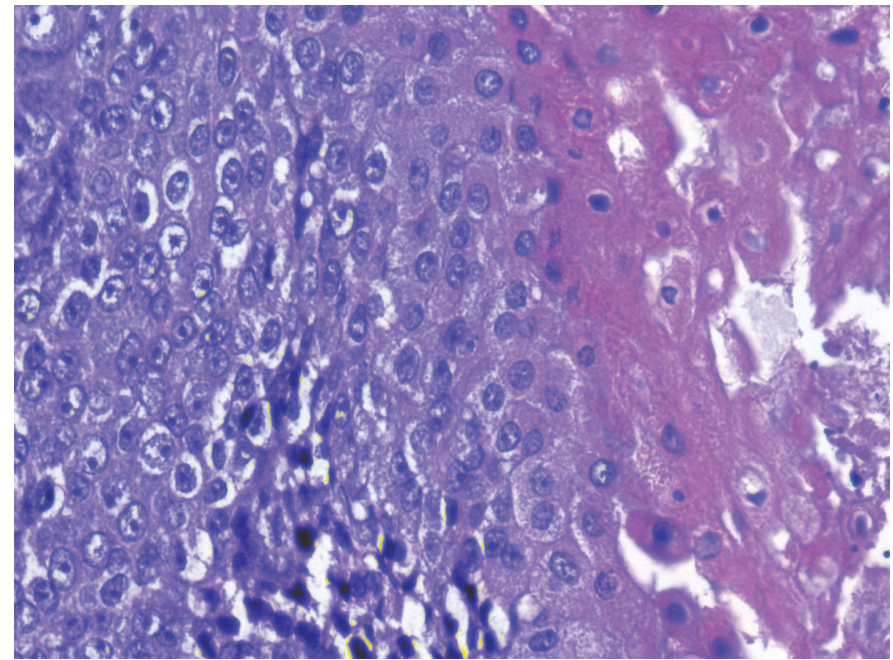

Figure 3 | Transformation of basaloid cells into ghost cells following the loss of their nuclei (the transformation zone), H\&E $\times 40$.

phatic liquid, some authors use the term pseudobulla $(5,6,10)$.

In our case, there was a clinically bullous-like appearance, but histopathologically there were not dilated lymphatic vessels, lymphoedema, or a real blister formation. Therefore, like the case that Akarsu et al. reported, our case was diagnosed as pseudobullous PM instead of bullous PM.

Because PM is only rarely seen and has various different clinical types, it is generally not included in preoperative diagnoses. The diagnosis may be assisted by a fine-needle aspiration biopsy and radiological imaging methods prior to the excision. However, the definite diagnosis is made based on histopathological examination $(1,11)$.

\section{Conclusion}

In conclusion, the bullous and pseudobullous appearances are rare clinical types of PM. PM should be considered prior to surgery in bullous and bullous-like lesions, and total excision should be performed for the diagnosis and treatment of the lesions.
7. de Giorgi V, Alfaioli B, Massi D, Gori A, Sestini S, Papi F et al. Bullous pilomatricoma: a particular and rare dermal bullous disorder. Acta Derm Venereol. 2009;89:189-90.

8. Karadağ AS, Ekşioğlu M, Özlük E, Akbay G, Eken A, Serel S, et al. A rare case of pilomatricoma with bullous appearance. Turk J Med Sci. 2009;39:333-6.

9. Fetil E, Soyal MC, Menderes A, Lebe B, Güneş AT, Ozkan S. Bullous appearance of pilomatricoma. Dermatol Surg. 2003;29:1066-7.

10. Belliappa P, Umashankar N, Raveendra L. Bullous pilomatricoma: a rare variant resembling bouncy ball. Int J Trichology. 2013;5:32-4.

11. Sinhasan SP, Jadhav CR, Bhat RV, Amaranathan A. Pilomatrixoma - presented as hypopigmented tender nodule: diagnosed by FNAC: a case report with review of literature. Indian J Dermatol. 2013;58:405. 